\title{
A Retro-prospective Study of Various Clinical Presentations of Isolated Left Sided Hepatolithiasis.
}

\author{
Dr. Mushtaq Ahmed ${ }^{1}$, Dr. O. J. Shah ${ }^{2}$, Dr. Chauhan Vinod kumar ${ }^{3}$,Dr. Mohd \\ Javed Bandey ${ }^{4}$ Dr.Shiv K.Sharma ${ }^{5}$ \\ ${ }^{I}$ Senior Resident General Surgery at Maharishi Markandeshwar Medical College and Hospital, Kumarhatti, \\ Solan. \\ ${ }^{2}$ Prof. and Head, Deptt. of Surgical gastroenterology at SKIMS, Srinagar. \\ ${ }^{3}$ Assistant Prof. General Surgery at Maharishi Markandeshwar Medical College and Hospital, Kumarhatti, \\ Solan. \\ ${ }^{4}$ Senior Resident at Deptt. of General Surgery at Govt Medical college Jammu. \\ ${ }^{5}$ Senior Resident General Surgery at Maharishi Markandeshwar Medical College and Hospital, Kumarhatti, \\ Solan.
}

\begin{abstract}
:
Objective: To study various clinical presentations and other related problems in left sided hepatolithiasis in a tertiary care centre at SKIMS, Srinagar.

Material and Methods: The present Retro-prospective study was conducted in the Department of Surgical Gastroenterology and Medical Gastroenterology of Sher-I - Kashmir Institute of Medical Sciences, Srinagar from May 2003 to December 2011. A total number of 80 cases were included in this study. Patient's data was analysed for their age and sex distribution, presenting symptoms, duration of disease and biochemical profile. Results: A total of 80 cases were studied in this series. Out of which, 51 cases were females and 29 cases were males. Male to female ratio was 1: 1.76. Their age at presentation was in range of 19-60 years with mean age at presentation being 38.08 years in males and 37.75 years in females. Abdominal pain was the principal presenting complaint experienced by $70 \%$ of patients. Other presentations were cholangitis (13.75\%), liver abscess (5\%), jaundice (3.75\%), incidental (3.75\%), cholecystitis $(2.5 \%)$ and acute pancreatitis $(2.5 \%)$. Assosciated clinical conditions seen were cloledocholithiasis (17.5), cholelithiasis(22.5\%), splenomegaly (3.75\%). Duration of illness was $<1$ month in $13.75 \%, 1$ month - 1year in $32.5 \%$ and $>1$ year in $53.75 \%$. Cases in present study had significantly raised serum bilirubin, serum alkaline phosphatase and alanine aminotransferase preoperatively. Hemoglobin, serum proteins, serum albumin and prothrombin levels were not significantly deranged.

Conclusion: Hepatolithiasis is endemic in Kashmir. Ascariasis is a common attributable risk factor in the present study. In endemic areas of ascariasis measures like improvement in personel hygiene, sanitation and regular deworming may lower the incidence of biliary ascariasis which inturn will reduce the occurrence of hepatolithiasis.
\end{abstract}

Key words: Hepatolithiasis, Ascariasis, Risk factor, Clinical presentation.

\section{Introduction}

Hepatolithiasis, also known as Recurrent pyogenic cholangitis(RPC), Oriental biliary obstruction syndrome and Oriental cholangiohepatitis $(\mathrm{OCH})$ refers to concretions existing in intrahepatic duct proximal to confluence of right and left hepatic ducts ${ }^{1}$, irrespective of co-existence of choledocolithiasis and/or cholecystolithiasis ${ }^{2}$. Hepatolithiasis most commonly affect the left hepatobiliary system because left hepatic duct has a more acute angle than the right hepatic duct ${ }^{3}$.

Intrahepatic stones are prevalent in South East Asia, Korea, Malaysia and $\mathrm{Japan}^{4}$ and in patient's undergoing surgery for gallstones; incidence is reported to be around $20-30 \%$. The disease is characterized by its intractable nature and frequent recurrences; requiring multiple operative interventions.

Etiology of intrahepatic stones is still a widely debated topic. In Western world, intrahepatic stones are regarded as secondary to the stones originating in gallbladder or primarily resulting from benign strictures, sclerosing cholangitis, choledocal cyst or malignant biliary tumours ${ }^{4}$. In East, however. majority of cases are associated with recurrent pyogenic cholangitis( RPC ${ }^{6}$ seen primarily in regions with prevalent parasitic infestation especially clonorchis sinensis and ascarias lumbricoides ${ }^{7}$. Biliary ascariasis is a common cause of biliary and pancreatic disease in an endemic area like ours ${ }^{8}$. 
"Charcot's triad" of jaundice, right upper quadrant pain and fever with chills is the commonest presentation, seen in $2 / 3^{\text {rd }}$ of cases. Other complaints include abdominal discomfort and vomiting. About $16 \%$ cases remain asymptomatic. Patients can present with complications including sepsis, recurrent cholangitis and intra-hepatic abscess. Some patients may develop devastating complications like liver atrophy and secondary biliary cirrhosis and can even progress to epithelial dysplasia and cholangiocarcinoma ${ }^{9,10,11}$.

\section{Material And Methods}

The present Retro-prospective study was conducted in the Department of Surgical Gastroenterology and Medical Gastroenterology of Sher- I - Kashmir Institute of Medical Sciences, Srinagar from May 2003 to December 2011. A total number of 80 cases were included in this study. Patient's data was analysed for their age and sex distribution, presenting symptoms, duration of diseases and biochemical profile.

\section{Results}

\begin{tabular}{|c|c|c|c|c|}
\hline \multicolumn{5}{|c|}{ Table 1: Age and Gender Distribution of the 80 patients who underwent left hepatic resection for isolated left } \\
hepatolithiasis. \\
\hline \multirow{2}{*}{ Age } & \multicolumn{2}{|c|}{ Male } & \multicolumn{2}{c|}{ Female } \\
\cline { 2 - 5 } & $\mathrm{n}$ & 6.89 & 4 & $\%$ \\
\hline 18 to 20 & 2 & 10.34 & 7 & 7.84 \\
\hline 21 to 30 & 3 & 34.48 & 16 & 13.72 \\
\hline 31 to 40 & 10 & 27.58 & 13 & 31.37 \\
\hline 41 to 50 & 8 & 20.68 & 11 & 25.49 \\
\hline 51 to 60 & 6 & 36.25 & 51 & 21.56 \\
\hline Total & 29 & \multicolumn{3}{c|}{$37.75 \pm 11.92$} \\
\hline mean \pm SE & \multicolumn{2}{|c|}{$38.08 \pm 12.12$} & \\
\hline
\end{tabular}

Table 1. A total of 80 patients were studied in this series, 51 were females and 29 males. Male to female ratio was 1:1.76. Their age at presentation was in the range of 19-60 years with mean age at presentation being 38.08 years in males and 37.75 years in females.

\begin{tabular}{|c|c|c|c|}
\hline \multicolumn{4}{|c|}{ Table 2: Clinical Profile of the Studied Subjects } \\
\hline \multicolumn{2}{|c|}{ Clinical Profile } & $\mathrm{n}$ & $\%$ \\
\hline \multirow{7}{*}{ Mode of Presentation } & Abdominal pain & 55 & 68.7 \\
\hline & Cholangitis & 11 & 13.7 \\
\hline & Liver Abscess & 4 & 5 \\
\hline & Jaundice & 3 & 3.7 \\
\hline & Incidental & 3 & 3.7 \\
\hline & Cholecystitis & 2 & 2.5 \\
\hline & Acute Pancreatitis & 2 & 2.5 \\
\hline \multirow{3}{*}{ Assosciated conditions seen } & Clolelithiasis & 18 & 22.5 \\
\hline & Choledocholithiasis & 14 & 17.5 \\
\hline & Splenomegaly & 3 & 3.7 \\
\hline \multirow{3}{*}{ Duration of illness } & $<1$ month & 11 & 13.7 \\
\hline & 1 month-1year & 26 & 32.5 \\
\hline & $>1$ year & 43 & 53.7 \\
\hline
\end{tabular}

Table 2. Abdominal pain was the principal presenting complaint experienced by $70 \%$ of patients. Other presentations were cholangitis $(13.75 \%)$, liver abscess $(5 \%)$, jaundice $(3.75 \%)$, incidental (3.75\%), cholecystitis

$(2.5 \%)$ and acute pancreatitis (2.5\%). Assosciated clinical conditions seen were cloledocholithiasis (17.5), cholelithiasis(22.5\%), splenomegaly (3.75\%). Duration of illness was <1 month in $13.75 \%, 1$ month - 1year in $32.5 \%$ and $>1$ year in $53.75 \%$.

\begin{tabular}{|c|c|c|c|}
\hline \multicolumn{4}{|c|}{ Table 3: Lab Parameters of the Studied Subjects } \\
\hline & & $\mathrm{n}$ & $\%$ \\
\hline \multirow{3}{*}{ DLC } & Normal & 73 & 91.3 \\
\hline & Eosinophelia & 4 & 5.0 \\
\hline & Neutrophelia & 3 & 3.7 \\
\hline \multirow{2}{*}{ TLC } & Normal & 72 & 90.0 \\
\hline & High & 8 & 10.0 \\
\hline Urea & Normal & 78 & 97.5 \\
\hline
\end{tabular}




\begin{tabular}{|c|c|c|c|}
\hline & High & 2 & 2.5 \\
\hline \multirow{2}{*}{ Creatinine } & Normal & 75 & 93.8 \\
\hline & High & 5 & 6.3 \\
\hline \multirow{3}{*}{ Bilirubin } & Raised & 23 & 28.8 \\
\hline & Normal & 57 & 71.3 \\
\hline & Range & \multicolumn{2}{|c|}{$0.3-18.3$} \\
\hline \multirow{3}{*}{ ALT } & Raised & 23 & 28.7 \\
\hline & Normal & 57 & 71.3 \\
\hline & Range & \multicolumn{2}{|c|}{$20-318$} \\
\hline \multirow{3}{*}{ AST } & Raised & 21 & 26.2 \\
\hline & Normal & 59 & 73.7 \\
\hline & Range & \multicolumn{2}{|c|}{$19-340$} \\
\hline \multirow{3}{*}{ ALP } & Raised & 54 & 67.5 \\
\hline & Normal & 26 & 26.5 \\
\hline & Range & \multicolumn{2}{|c|}{$125-983$} \\
\hline \multirow{3}{*}{ Total Protein } & Low & 31 & 38.7 \\
\hline & Normal & 49 & 61.2 \\
\hline & Range & \multicolumn{2}{|c|}{$5.5-9.6$} \\
\hline \multirow{3}{*}{ Albumin } & Low & 32 & 40 \\
\hline & Normal & 48 & 60 \\
\hline & Range & \multicolumn{2}{|c|}{$2.8-4.9$} \\
\hline
\end{tabular}

Table 3. Patients in our study had significantly raised serum bilirubin, serum alkaline phosphatase and alanine aminotransferase preoperatively. Hemoglobin, serum proteins, serum albumin and prothrombin levels were not significantly deranged.

\section{Discussion}

Hepatolithiasis most commonly affect the left hepatobiliary system because left hepatic duct has a more acute angle than the right hepatic duct ${ }^{3}$.

According to the literature, hepatolithiasis has equal distribution in both the sexes and usually affects $3^{\text {rd }}$ to $7^{\text {th }}$ decade of life ${ }^{5}$. But in our study male:female ratio was around $1: 1.76$ which is probably because of high prevalence of Ascariasis in the Kashmiri female population ${ }^{12}$.

The presence of dead Ascaris lumbricoides within stones has shed further light on the pathogenesis of this disease in areas without clonorchiasis ${ }^{13}$. Not only do they lead to inflammation resulting in injury to biliary epithelium, the presence of parasitic fragments or their eggs can act as a nidus for intra-hepatic stone formation. In our study $7.5 \%$ of patients had ascaris lumbricoids fragments in intrahepatic ducts.

Abdominal pain either in right upper quadrant or in upper abdomen is the most common presentation. "Charcot's triad" (jaundice, right upper quadrant pain and fever with chills) is the form of presentation in about 2/3rd of cases. Abdominal discomfort and vomiting are the other associated complaints. Asymptomatic cases constitute about $16 \%$ of total cases. Patient can present with complications like recurrent cholangitis, sepsis, intrahepatic abscess and may develop liver atrophy and secondary biliary cirrhosis. Physical examination often reveals epigastric tenderness, rigidity, and enlargement of the liver and gallbladder. Icterus is present in $77 \%$ of patients $^{14}$

In the present study, abdominal pain was the principal presenting complaint experienced by $70 \%$ of patients. Other presentations were cholangitis $(13.75 \%)$, liver abscess $(5 \%)$, jaundice (3.75\%),incidental (3.75\%),cholecystitis $(2.5 \%)$ and acute pancreatitis (2.5\%). Assosciated clinical conditions seen were cloledocholithiasis (17.5), cholelithiasis (22.5\%), splenomegaly (3.75\%). The results of clinical presentations shown by present study were comparable to the study conducted by O.J. Shah et al ${ }^{\mathbf{1 5}}$; acute cholangitis(12.7\%), abdominal pain(70.9\%), jaundice((3.6\%), acute pancreatitis(2.7), liver abscess (3.6\%)' subphrenic abscess( $(0.9 \%)$, cholecystitis $(2.7 \%)$, incidental( 2.7$)$ and other assoscited diseases seen were gall stones(20\%),common bile duct stones(18.1\%), ascariasis(7.3\%), esophagial varices $(2.7 \%)$,splenomegaly (3.6\%). The present study showed duration of illness $<1$ month in $13.75 \%, 1$ month - 1year in $32.5 \%$ and $>1$ year in $53.75 \%$ of patients.

\section{Conclusion}

Hepatolithiasis is endemic in Kashmir. Ascariasis is the common attributable risk factor in the present study. In endemic areas of ascariasis measures like improvement in personel hygiene, sanitation and regular deworming may lower the incidence of biliary ascariasis which inturn will reduce the occurrence of hepatolithiasis.

\section{Reference}

[1]. Intrahepatic stones. Blumgart Surgery of liver and biliary tract. J Kamaya, Kitagava, Y.Nimura Ed. $3^{\text {rd }}$, page 815. L.B.Saunders.

[2]. Yridium Osman et al. Hepatic segementectomy for hepatolithiasis; Case report and review of literature. Turkish Journal of gastroentology 2000; vol. 11:No.1 
[3]. Simi M, Loriga P, Basoli A, et al. (1979) Intraphepaticlithiasis: Study of thirty six cases and review of literature. AM J Surg 8:36-40

[4]. Nakayama F, Koga A. Hepatolithiasis present status. World journal of Surgery 1984;8:9:11

[5]. Nakayama F. Hepatolithiasis in East Asia. Digestive Disease and Sciences 1986;30(1):25-26.

[6]. Cook J, Hou PC, Ho HC, McFadzean AJ. Recurrent pyogenic cholangitis. British J Surgery 1954;42:188-203.

[7]. Yellin AE et al. Biliary Lithiasis and helm intholiasis. Am JSurg 1981;142:128.

[8]. Khuroo MS, Zargar SA. Biliary ascariasis, a common cause of biliary and pancreatic disease in an endemic area. Gastroenterology $1985,88,418-423$

[9]. Tanumura et al 1994. Epidemiology of hepatolithiasis in Japan. In Japanse Govt. Annual Reports of Japanese Ministry of H\&W. Tokoyo, Japan:17-27 (In Japanese).

[10]. Fan ST et al. Treatment of hepatolithiasis: Improvement of result by a systematic approach. Surg 1991;109:474-80

[11]. Chigiiwa K et al. Current management and long-term prognosis of hepatolithiasis. Arch Surg 1995;130: 194-7.

[12]. Khuroo MS, Zargar SA, Mahajan R. Hepatobiliary and pancreatic ascariasis in India. Lancet 1990(Sept)-29,366(8718):811-2.

[13]. Teoh TB.A study of gall stones and included worms in recurrent pyogenic cholangitis. J Path Bact 1963; 86:123-129.

[14]. Ong GB. A study of recurrent pyogenic cholangitis. Arch Surg 1962; 84:199-225.

[15]. Omar J.S. et al. Left-sided hepatic resection for hepatolithiasis; a longitudinal study of 110 patients. International Hepato-PancreatoBiliary Association2012; 14, 764-771. 